\title{
Produtos artesanais de identidade territorial: o desenvolvimento do patrimônio natural e cultural na comunidade Mocambeiro - Brasil
}

\author{
Productos artesanales de identidad territorial: o desarrollo del patrimonio \\ natural y cultural en la comunidad Mocambeiro - Brasil \\ Artisanal products of territorial identity: the development of natural and \\ cultural heritage in the community Mocambeiro - Brazi
}

Rita de Castro Engler ${ }^{1}$

Nadja Maria Mourão ${ }^{2}$

Marília de Fátima Dutra de Ávila Carvalho ${ }^{3}$

Rosilene Conceição Maciel $^{4}$

\begin{abstract}
Resumo
Este trabalho apresenta parte dos resultados da pesquisa extensionista realizada na comunidade Mocambeiro, Matozinhos, Minas Gerais, entre 2015 e 2016, cidade em que o CEDTec, Centro de Estudos em Design e Tecnologia, promoveu oficinas de produtos artesanais de identidade territorial, inspirados nas figurações rupestres das grutas, abrigos e cavernas pré-históricas, ali existentes. A proposta busca valorizar o trabalho de produção artesanal da população local, principalmente as donas de casa, buscando ligação com a arte e o design. Realiza-se a contextualização dos símbolos do patrimônio arqueológico da região cárstica da APA (Área de Proteção Ambiental) de Lagoa Santa. A memória cultural, história e patrimônio arqueológico são abordados, através das oficinas de educação e arte, em um ambiente de troca, aprendizado e aperfeiçoamento para novas atividades, que estimulem a geração de renda e o empreendedorismo. Os procedimentos para a execução do projeto se dividem em três etapas: estudos para elaboração de oficinas e desenvolvimento de produtos, utilizando os materiais que possam ser encontrados na região de Matozinhos; desenvolvimento de oficinas para a comunidade de Mocambeiro e avaliação das atividades; desenvolvimento de produtos, a partir dos resultados, destinados a servirem se suporte para a continuidade do projeto, valendo-se da identidade local. Foi verificada a possibilidade de produção criativa e novas áreas de atuação do design nas comunidades artesãs, práticas indispensáveis à construção de valorização do artesanato local, atual e do futuro.
\end{abstract}

Palavras-Chave: Artesanato; diversidade cultural; empreendedorismo; identidade; patrimônio.

\footnotetext{
${ }^{1}$ PhD Gestão de Inovação Tecnológica/ECP França; Coord. Programa de Pós-Graduação em Design - PPGD da Universidade do Estado de Minas Gerais - UEMG; Belo Horizonte, Minas Gerais/Brasil; rcengler@uol.com.br.

${ }^{2}$ Mestre em Design pela ED-UEMG/Brasil. Doutoranda em Design; Centro de Estudos em Design e Tecnologia da Escola de Design - CEDTec da Universidade do Estado de Minas Gerais - UEMG; Belo Horizonte; Minas Gerais/Brasil; nadjamourao@gmail.com.
}

${ }^{3}$ Dra. Arquitetura pela NPGAU-UFMG/Brasil; Pós-Doutoranda em Design e Tecnologia/ CAPES/; lotada no CEDTec da Universidade do Estado de Minas Gerais - UEMG; Belo Horizonte, Minas Gerais/Brasil; mariliadefatimaavilacarvalho@gmail.com

\footnotetext{
${ }^{4}$ Mestre em Gestão Integrada doTerritório pela UNIVALE / Brasil. Doutoranda em Design; Centro de Estudos em Design e Tecnologia da Escola de Design - CEDTec da Universidade do Estado de Minas Gerais - UEMG; Belo Horizonte; Minas Gerais/Brasil; rmaciela@gmail.com
} 


\begin{abstract}
Resumen
Este trabajo presenta parte de los resultados de la investigación extensionista realizada en la comunidad Mocambeiro, Matozinhos, Minas Gerais, entre 2015 y 2016, ciudad en la que el CEDTec, Centro de Estudios en Diseño y Tecnología, promovió talleres de productos artesanales de identidad territorial, inspirados en las figuraciones Rupestres de las cuevas, abrigos y cuevas prehistóricas, allí existentes. La propuesta busca valorar el trabajo de producción artesanal de la población local, principalmente las amas de casa, buscando conexión con el arte y el diseño. Se realiza la contextualización de los símbolos del patrimonio arqueológico de la región cárstica de la APA (Área de Protección Ambiental) de Lagoa Santa. La memoria cultural, historia y patrimonio arqueológico son abordados a través de los talleres de educación y arte, en un ambiente de intercambio, aprendizaje y perfeccionamiento para nuevas actividades, que estimulen la generación de ingresos y el espíritu emprendedor. Los procedimientos para la ejecución del proyecto se dividen en tres etapas: estudios para elaboración de talleres y desarrollo de productos, utilizando los materiales que puedan ser encontrados en la región de Matozinhos; Desarrollo de talleres para la comunidad de Mocambo y evaluación de las actividades; Desarrollo de productos, a partir de los resultados, destinados a servir si se apoya para la continuidad del proyecto, valiéndose de la identidad local. Se verificó la posibilidad de producción creativa y nuevas áreas de actuación del diseño en las comunidades artesanas, prácticas indispensables para la construcción de valorización de la artesanía local, actual y del futuro
\end{abstract}

Palabras claves: Artesanía; diversidad cultural; el empresario; de la identidad; el patrimonio.

\begin{abstract}
This work presents part of the results of an extension research carried out in the Mocambeiro community, Matozinhos, Minas Gerais, between 2015 and 2016, a city in which CEDTec, a Center for Studies in Design and Technology, promoted workshops on handicraft products with a territorial identity, inspired by figurations Prehistoric caves, caves and caves, existing there. The proposal seeks to value the work of artisan production of the local population, especially housewives, seeking to link with art and design. The contextualisation of the symbols of the archaeological patrimony of the APA (Environmental Protection Area) karst region of Lagoa Santa is carried out. Cultural memory, history and archaeological heritage are approached, through education and art workshops, in an environment of exchange, learning and improvement for new activities, which stimulate income generation and entrepreneurship. The procedures for the execution of the project are divided into three stages: studies for the preparation of workshops and product development, using the materials that can be found in the Matozinhos region; Development of workshops for the community of Mocambeiro and evaluation of activities; Development of products, based on the results, intended to serve as support for the continuity of the project, using the local identity. The possibility of creative production and new areas of design performance in the artisan communities, practices indispensable to the construction of valorization of the local craftsmanship, current and of the future, was verified.
\end{abstract}

Keywords: Crafts; cultural diversity; entrepreneurship; identity; patrimony.

\title{
1. Introdução
}

Este artigo apresenta parte dos resultados da pesquisa extensionista realizada na comunidade Mocambeiro, Minas Gerais (Brasil), entre 2015 e 2016, cidade em que a Escola de Design da Universidade do Estado de Minas Gerais promoveu oficinas de produção de produtos artesanais com identidade territorial, inspirados nas figurações rupestres das grutas, abrigos e cavernas pré-históricas, ali existentes. Para valorizar a identidade territorial dessa região cárstica, de grande beleza cênica, realizou-se trabalho participativo com a população da comunidade, com articulações culturais entre turismo ecológico, cultura, memória, artesanato. 
Nas últimas décadas, o desenvolvimento econômico local tem sido tratado juntamente com cultura. O processo de "culturalização" da economia vem ganhando contribuições teóricas no cenário mundial, cujas aplicações em projetos de desenvolvimento territorial de base local tem sido relevante. Considerou-se, aqui, a cultura como "campo interconectado, reconfigurado por novas identificações globais e locais, em que se negociam as bases para uma interculturalidade de inclusão em forma de rede" (CANCLINI, 2005, p. 21).

O uso da cultura como recurso foi o processo norteador dessa pesquisa, podendo funcionar enquanto agente para a melhoria das condições sociais, estimuladora do crescimento econômico, urbano e turístico. Conforme Yúdice (2004) paralelo a essa investida, aconteceu uma redução de investimentos no setor social que levou, entre outras consequências, à expansão da cultura para as esferas econômica e política. Assim, o setor cultural tornou-se um aglutinador de ações para o desenvolvimento socioeconômico de base local.

A capacidade da comunidade local de gerar empregos e renda foi uma possibilidade visualizada, por meio das práticas artesanais com aplicação da identidade local, num território que tem sido visitado por turismo ecológico e turismo de romaria. O turismo, na comunidade do Mocambeiro, está começando a crescer e a visitação num ambiente com cavernas, grutas e abrigos rochosos que necessitam de proteção, requer ações educativas junto à comunidade, sobre noções de preservação, cuidados com a paisagem, com as comunidades locais, com o patrimônio natural e cultural. Neste trabalho apresenta-se a comunidade do Mocambeiro, localizada numa paisagem cárstica de grande beleza cênica, cujo patrimônio natural e cultural é bastante visitado por turistas, demonstrando vocação para o turismo. Conforme Armond (2012), a visitação turística ao patrimônio arqueológico e espeleológico do Mocambeiro é importante para que o público em geral conheça as cavernas, grutas, abrigos e dolinas e compreenda a importância e fragilidade destes ambientes e aprenda a preservá-los.

Adotou-se, neste projeto, a concepção antropológica de cultura, entendida como o conjunto de práticas e saberes que constituem os modos específicos da vida de um povo. Cultura é um conjunto de signos de cada comunidade e de toda a nação. Concordamos com Gil (2003), que cultura resulta do sentido dos nossos atos, a soma de nossos gestos, o senso de nossos jeitos.

Cada cultura tem suas próprias e distintivas formas de classificar o mundo. Por meio da construção de sistemas classificatórios, a cultura propicia os recursos pelos quais podem 
dar sentido ao mundo social e construir significados. Conforme Woodward (2000, p. 4), há entre os membros de uma sociedade, certo grau de consenso sobre como classificar os objetos no ambiente, a fim de manter alguma ordem social. Esses sistemas partilhados de significação são, na verdade, o que se entende por "cultura".

A preservação dos elementos constitutivos da memória dos grupos habitantes do Mocambeiro é condição para a construção e para a consciência de suas identidades, compreendidas e formuladas de maneira autônoma. De acordo com Le Goff (2003), grupos ou indivíduos que perdem a memória do que foram e fizeram perdem suas identidades e, nesse processo, tornam-se reféns daqueles grupos ou indivíduos que detêm a memória. Dos moradores de Mocambeiro, priorizou-se atenção às mulheres, por sua história de sofrimentos decorrentes da desigualdade de gênero. Desde a época do Brasil colônia, mulheres que, apesar de sofridas, vêm exercendo grande luta pela modificação de seus papéis na sociedade.

Este projeto, por questões práticas, acreditou no empoderamento da população local. Aliaram-se as técnicas artísticas e o design ao repertório de produção artesanal oriundo da comunidade. A questão pesquisada foi o desenvolvimento didático para trabalhar o conhecimento em design e investigação sobre empreendedorismo, de forma a servir para aumentar perspectivas econômicas da população, principalmente para as mulheres que atuam em atividades domésticas.

O empreendedorismo social é atualmente a chave para o desenvolvimento sustentável e desenvolvimento da economia local, principalmente em comunidades de baixa renda. Ele está delineando novos meios de trabalho e de solução de problemas coletivos. Ou seja, o objetivo final da iniciativa não é apenas a geração de lucro, mas o impacto na sociedade que ela produz conforme Mourão et al (2016).

Pensando na geração de produtos artesanais de identidade territorial na comunidade do Mocambeiro buscou-se pesquisar, analisar e desenvolver possibilidades de estímulo ao empreendedorismo, por meio da produção criativa e artística aplicadas ao artesanato, para melhoria da qualidade de vida de mulheres de baixa renda ali residentes.

A memória cultural, história e patrimônio arqueológico foram abordados, através das oficinas de educação em arte, em um ambiente de troca, aprendizado e aperfeiçoamento para novas atividades artesanais, que estimulem a geração de renda e o empreendedorismo.

Os procedimentos para a execução do projeto se dividiram em três etapas: a primeira etapa, estudos para elaboração de oficinas e criação de produtos artesanais, utilizando os 
materiais encontrados na região de Matozinhos. A segunda etapa, desenvolvimento de oficinas para a comunidade e avaliação das atividades. E a terceira etapa, produção de protótipos artesanais, a partir dos resultados, destinados a servirem de suporte para a continuidade do projeto, com identidade local e criatividade.

\section{2. Área de Proteção Ambiental - Mocambeiro}

Na comunidade de Mocambeiro uma parte expressiva da população é de negros e descendentes, que ali se fixaram desde os tempos coloniais. Fica aproximadamente a $46 \mathrm{~km}$ de Belo Horizonte; pertence à Região Cárstica de Lagoa Santa e é um riquíssimo sítio arqueológico, com diversas pinturas rupestres.

Conforme Berbert-Born (2000) o carste de Lagoa Santa é uma região identificada pela ocorrência de um denso conjunto de feições geomorfológicas tipicamente dissolutivas e por uma hidrografia que pode ser caracterizada como mista de componentes fluviais (subaéreos) e cársticos (subterrâneos), como ilustra a figura 1.

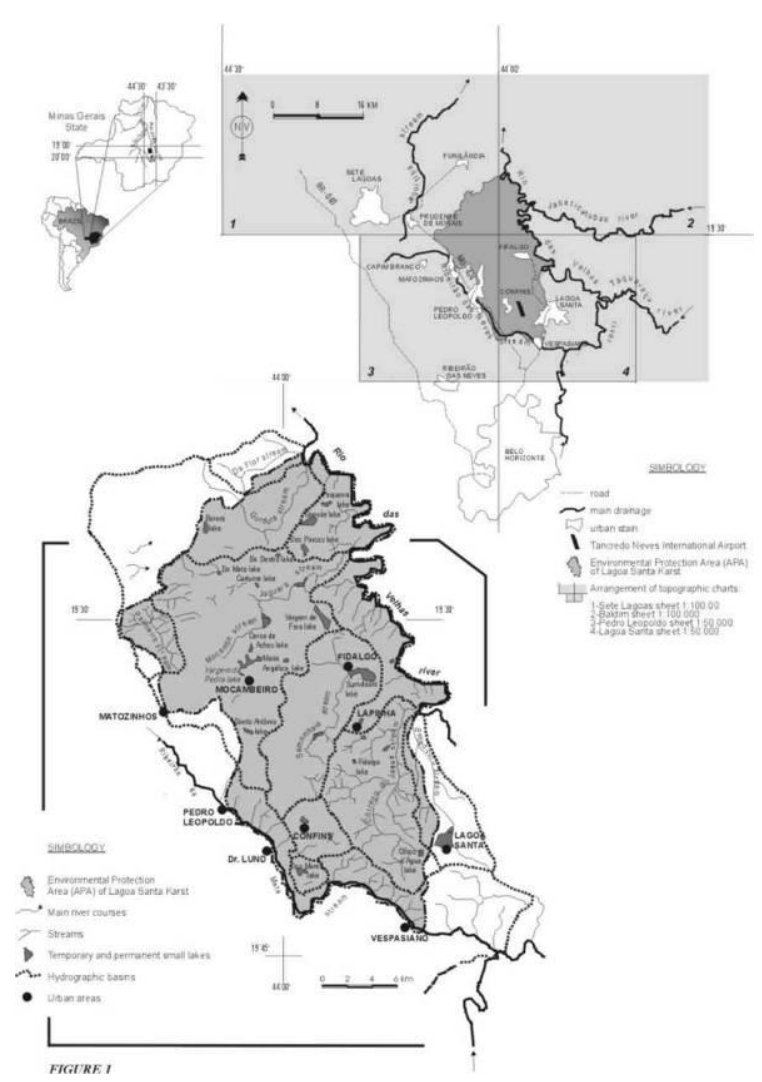

Figura1 - Carste de Lagoa Santa

Fonte: BERBERT-BORN, 2000 
O distrito de Mocambeiro situa-se dentro da Área de Proteção Ambiental - APA Carste Lagoa Santa, “[...] importante sítio arqueológico, com pinturas rupestres, cujo conjunto do patrimônio natural, constituído pela dolina, abrigo e caverna, conforma uma paisagem de grande beleza cênica" (BAETA et al, 2009, p.6).

Além desse projeto de incentivo ao artesanato local, há outras atividades para incrementar o desenvolvimento local, a exemplo do projeto Trilha Parque Vale do Mocambo, que faz parte de um conjunto de iniciativas que busca trazer para a comunidade de Mocambeiro o desenvolvimento sustentável do ecoturismo, divulgando as atrações históricas, culturais e naturais deste grande parque natural. Os realizadores deste projeto de ecoturismo visam trabalhar em parceria com a comunidade do Mocambeiro, oferecendo oportunidades de divulgação dos produtos artesanais de identidade territorial em pousadas, bares, restaurantes, grupos de doceiras, fazendeiros, sitiantes de aluguel e outros, que tenham algo para mostrar e oferecer a quem vem visitar a região, conforme Armond (2012).

Dentre as 200 grutas existentes na Área de Proteção Ambiental Carste, se encontra a gruta do Ballet, Patrimônio Arqueológico e Espeleológico de Minas Gerais. Essa gruta é parte integrante do Conjunto Poções, tombado pelo IEPHA/MG ${ }^{5}$ desde 1996, que tem o registro do Ritual da Fecundidade (painel de figurações rupestres, que demonstram uma gestação e um possível parto, acompanhados de um ritual de dança), ilustrações de vivências de homens e mulheres que habitavam a região na Pré-História, segundo registros de Kohler (1989).

Os registros sobre a fecundação em pintura rupestre são muito importantes, pois só existem três descobertos e mantidos como patrimônio em todo o mundo. Encontram se ali também outras importantes grutas, como o conjunto Cerca Grande, que foi objeto de estudo do paleontólogo dinamarquês Peter Lund, além do Monumento Natural Estadual Vargem da Pedra, conforme CETEC (1980).

Essas formações de rocha calcária citadas pertencem atualmente ao Ecomuseu do Carste Minas Gerais, que revela a grande riqueza arqueológica e espeleológica da região, com destaque para as grutas Poções, Cerca Grande e Ballet.

\footnotetext{
${ }^{5}$ IEPHA/MG - Instituto Estadual do Patrimônio Histórico e Artístico de Minas Gerais. Criado pelo Governo do Estado, em 30 de setembro de 1971, é uma fundação sem fins lucrativos vinculada à Secretaria de Estado de Cultura de Minas Gerais - Brasil. Este instituto tem por finalidade pesquisar, proteger e promover os patrimônios cultural, histórico, natural e científico, de natureza material ou imaterial, de interesse de preservação no Estado de Minas Gerais, nos termos da legislação.
} 
RELACult - Revista Latino-Americana de Estudos em Cultura e Sociedade

Revista Latinoamericana de Estudios en Cultura y Sociedad | Latin American Journal of Studies in Culture and Society V. 03, ed. especial, dez., 2017, artigo $n^{\circ} 492$ | relacult.claec.org | e-ISSN: 2525-7870

\section{Desenvolvimento das atividades}

\subsection{Matozinhos e Mocambeiro: patrimônio, cultura e identidade}

O município de Matozinhos, com uma extensão territorial de 252,280 km2, possui uma população estimada em 37.040 habitantes (IBGE, 2010). Faz divisa com as cidades de Pedro Leopoldo, Prudente de Morais, Capim Branco, Esmeraldas, Baldim, Jaboticatubas, Funilândia, com acesso à capital pelas rodovias MG-10 e MG-424.

A cidade nasceu em torno da Igreja, construída para Senhor Bom Jesus do Matozinhos, seu padroeiro, após a sua imagem ter sido encontrada nas ruínas do acampamento da bandeira de Dom Rodrigo de Castelo Branco. A importância do Jubileu, no âmbito da cultura popular, é reconhecida oficialmente pelo seu registro como Patrimônio de Natureza Imaterial, indicado no Inventário de Proteção do Acervo Cultural - IPAC do município. É a festa mais tradicional e mais representativa do município, reconhecida pela comunidade como patrimônio imaterial, através do Conselho Municipal do Patrimônio Cultural (GOULART; TABULEIRO, 2007).

São realizadas missas e exposição do Santíssimo Sacramento durante todos os dias do evento, sendo que no último dia, a imagem santa é levada em procissão motorizada pelas ruas da cidade, com a participação da comunidade, em encenações bíblicas de Cristo (FIG. 2).

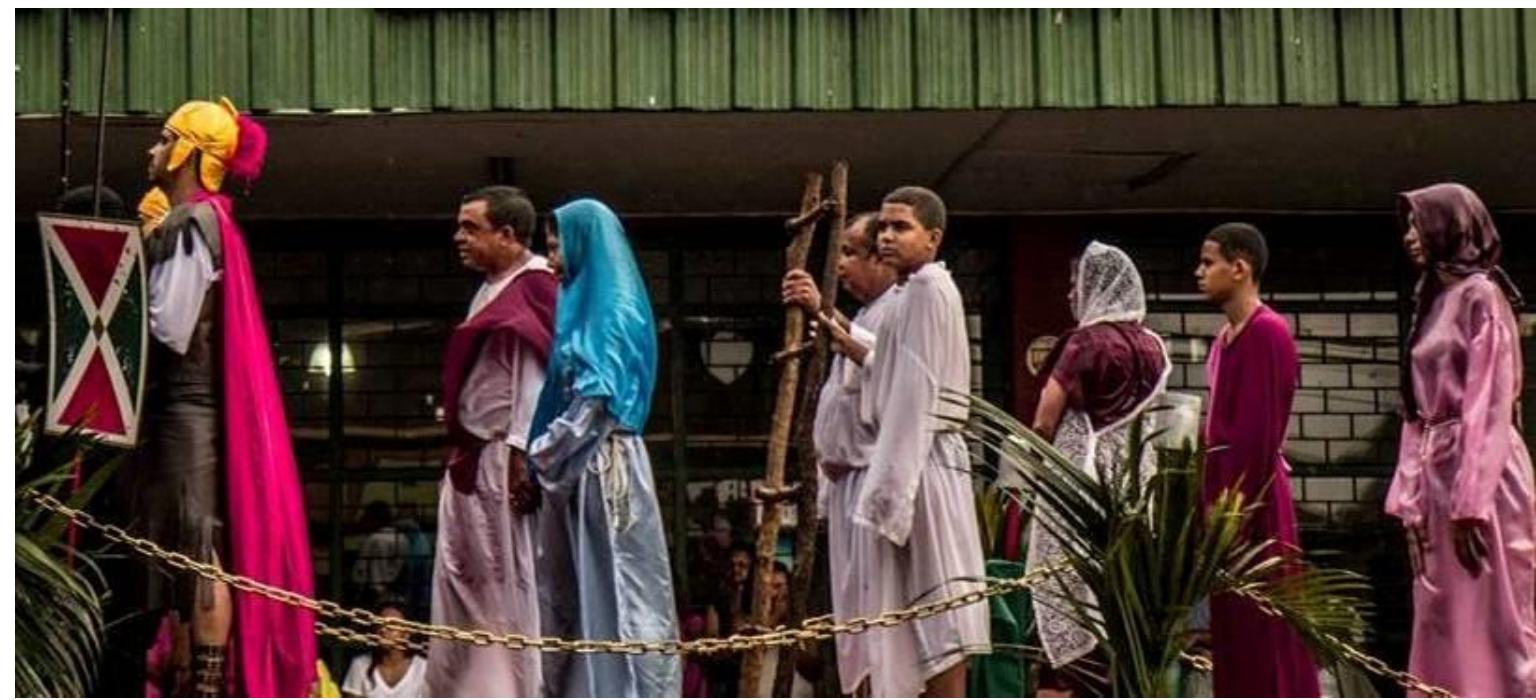

Figura 2 - Procissão motorizada do Jubileu de Matozinhos, com a participação da comunidade. Fonte: Laís Kunzendorff, 2015. 
Além da igreja matriz na praça principal, a cidade preserva algumas capelinhas de século XVIII, no estilo colonial mineiro, e também aa sede da estação da Estrada de Ferro Central do Brasil, do início do século XX. No distrito de Mocambeiro, encontra-se um importante patrimônio histórico, representado pelo Conjunto Arquitetônico da Fazenda da Jaguara. Tombado pelo IEPHA, este conjunto remete ao período colonial, conforme site da Prefeitura de Matozinhos.

Os moradores da região contam que a comunidade de Mocambeiro foi formada a partir da fuga de escravos vindos da extinta Fazenda Jaguara. Existe uma predominância de pessoas de origem africana entre seus moradores, que preservam as tradições, como o congado e reinado e suas festas tradicionais, reflexo do território e da identidade.

O conceito de território ultrapassa as dimensões materiais ou concretas, construído historicamente, remetendo a diferentes contextos e escalas, conforme Arantes (2004). Trata-se de um campo de forças, uma teia ou rede de relações sociais que se projetam no espaço. Dessa forma, o território é objeto de análise em diferentes perspectivas: geográfica, antropológicocultural, sociológica, econômica, jurídico-política, bioecológica, que o percebem, cada qual, segundo suas abordagens específicas.

O território assume ainda significados distintos em cada formação socioespacial. No mundo ocidental, o conceito de território foi de início centralmente associado à base física dos Estados, incluindo o solo, o espaço aéreo e as águas territoriais. Nas sociedades indígenas, apenas para citar um exemplo, o fundamental é o sentimento de identidade com a Terra-Mãe, sentimento esse baseado no conhecimento, no patrimônio cultural e nas relações sociais e religiosas que esses povos guardam com aquela parcela geográfica (ARANTES, 2004, p.19).

Conforme o sociólogo Milton Santos (2005), esse conceito, no mundo atual, deve se entender em todas as dimensões da vida humana, considerando inclusive, redes que se formam em tempo e espaço.

\footnotetext{
O território, hoje, pode ser formado de lugares contíguos e de lugares em rede: as redes constituem uma realidade nova que, de alguma maneira, justifica a expressão verticalidade. Mas além das redes, antes das redes, apesar das redes, depois das redes, com as redes, há o espaço de todos, porque as redes constituem apenas uma parte do espaço e o espaço de alguns. São, todavia, os mesmos lugares que formam redes e que formam o espaço de todos (SANTOS, 2005, p.5).
}

Por meio das fundamentações, o estudo relaciona estes conceitos com formação da identidade local. As identidades, na maioria das vezes, são construídas e reconstruídas no tempo e nas fronteiras com novas culturas. A identidade é o arquétipo a partir do qual os indivíduos e os grupos sociais constroem a idéia de quem são e estabelecem o padrão de 
relação com outros membros da própria espécie e com o ambiente, para garantir a sobrevivência e sucesso reprodutivo (KESTERING, 2007 apud CASTRO, 2010). "Cada grupo cultural tem um padrão de comportamento, tecnologia, gestos, hábitos e traços próprios de identidade. A pintura rupestre se enquadra como um objeto, que caracteriza diferenciadores que podem corresponder a determinados grupos” (CASTRO, 2010, p. 38).

Em Mocambeiro, de acordo com Granbel (2011), estão localizadas as ruínas da sede da Fazenda Jaguara, fundada em 1724. Foi um dos mais importantes estabelecimentos rurais do período do Brasil colônia. Nessa propriedade, havia um belo casarão, com casa de agregados, dependências de marcenaria, carpintaria, engenho, moinho d'água e galpões. No lugar, há ainda as ruínas da Igreja de Nossa Senhora da Conceição da Jaguara, construída em 1786, uma das poucas obras totalmente atribuídas ao mestre Aleijadinho, da qual apenas a fachada ainda resiste às intempéries. O autor descreve que na propriedade, em meio à densa vegetação do alto da colina, vê-se um castelo construído no início do século passado pelo inglês George Chalmers (nesse lugar atualmente há um canil de cães fila). Dentro do território montanhoso de Matozinhos, está o Pico da Roseira, com 1.011 metros de altitude, o ponto mais elevado da região, onde se encontra também a nascente do Ribeirão da Mata.

Armond (2012) relata que o Ecomuseu do Carste Mocambeiro é um rico patrimônio natural e cultural, com elementos naturais conhecidos mundialmente a partir de Peter Wilhelm Lund, em fins de século XIX. É um museu a céu aberto que tem como acervo formações cársticas, lagoas, estruturas arquitetônicas rurais de interesse histórico local e mundial, conforme figura 3 .

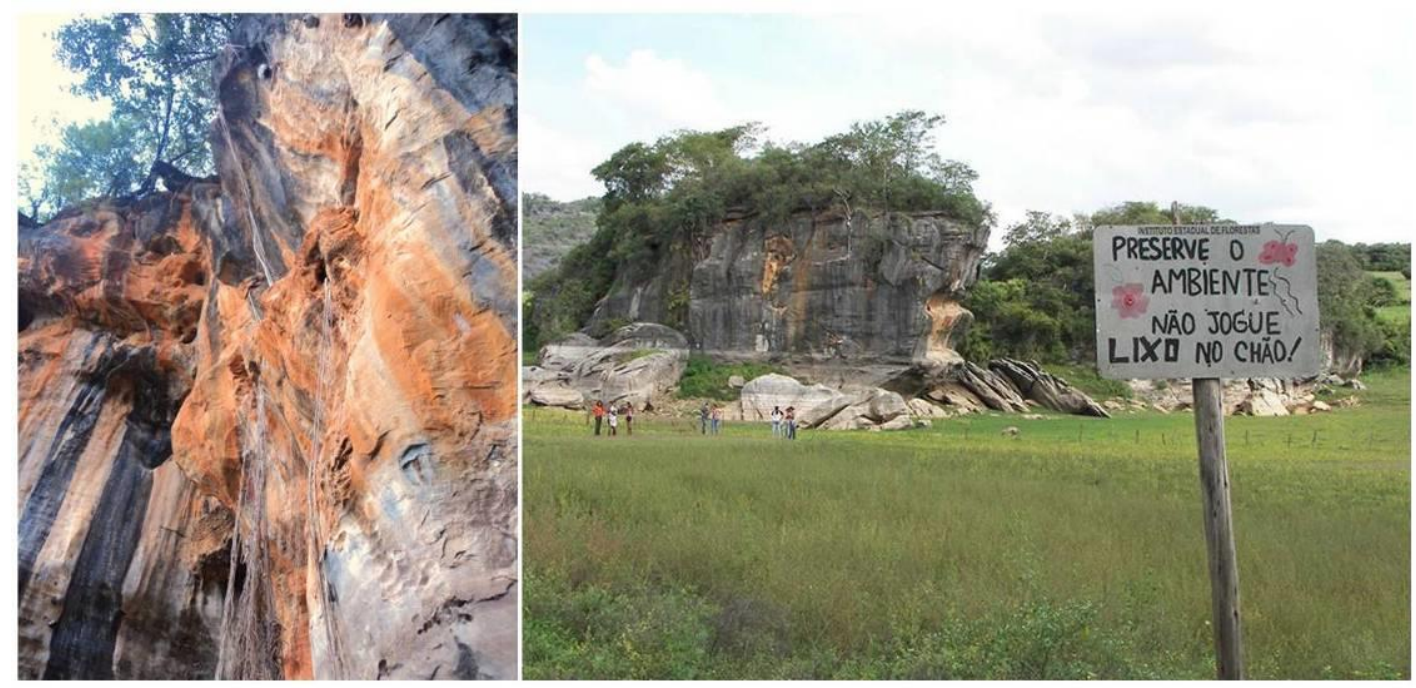

Figura 3 - Ecomuseu Cerca Grande, em Mocambeiro/ Minas Gerais - Brasil Fonte: Equipe da Pesquisa, 2016. 
O projeto Trilha Parque Vale do Mocambo faz parte de um conjunto de iniciativas que busca trazer para a comunidade de Mocambeiro o desenvolvimento sustentável do Eco Turismo, divulgando as atrações históricas, culturais e naturais deste grande potencial que vivemos. Os realizadores deste projeto visam trabalhar em parceria com a comunidade, e também, com pousadas, bares, restaurantes, doceiras, artesãos, fazendeiros, sitiantes de aluguel e outros, que tenham algo para mostrar e oferecer a quem vem visitar a região, conforme Armond (2012).

\subsection{Estudos de materiais e técnicas}

$\mathrm{Na}$ primeira etapa das oficinas de produtos artesanais de identidade territorial, os procedimentos para a execução do projeto consistiram em estudos da Arte Rupestre local e para elaboração e desenvolvimento de produtos artesanais, pesquisas sobre identidade local e criatividade.

As pinturas rupestres foram uma das primeiras formas de expressão utilizadas para a representação do ser humano e seu ambiente, no território. Internamente, as pinturas de ursos, rinocerontes e cavalos da caverna Chauvet, na pitoresca região de Ardeche, no sul da França, foram consideradas uma das mais antigas do mundo. Acredita-se que foram criadas por pessoas da cultura Aurignaciana, que viveram entre 28.000 e 40.000 anos atrás (SADIER et $a l, 2012)$.

Segundo levantamento de 2008, realizado pelo Instituto do Patrimônio Histórico e Artístico Nacional (IPHAN), o Brasil possui 14.000 sítios arqueológicos. Hoje, acredita-se que esse número já tenha saltado para 20 mil. Porém, desse total, somente 17 bens arqueológicos (11 sítios e 6 coleções) foram tombados e informados pelo IPHAN, conforme Domingues (2016).

Nos sítios arqueológicos encontram-se registros de arte rupestres, que exibem, em vários "estilos", técnicas e materiais uma iconografia variada. Geralmente, são representações de animais, pessoas e plantas e sinais gráficos abstratos, muitas vezes usados em combinação. Pereira (2011) relata que a interpretação desses sinais e desenhos é bastante complexa e está cercada de controvérsia. Mas, acredita-se, pelo comportamento humano, que possam ilustrar cenas de caça, ritual, cotidiano, ter caráter mágico, e expressar, como uma espécie de linguagem visual, conceitos, símbolos, valores e crenças. 
Enquanto os historiadores da arte lutaram com essas imagens e objetos, poucos cientistas pesaram sobre a arte paleolítica como artefatos de uma sociedade complexa e viva. Russell Dale Guthrie é um dos primeiros a fazer isso, em seu volume monumental The Nature of Paleolithic Art realiza um estudo que abre outra visão para a compreensão dessas imagens maravilhosas. Para ele, os registros nas cavernas era um exercício de criatividade.

As inscrições rupestres e outros remanescentes preservados dos povos paleolíticos lançam luz sobre um mundo pouco conhecido de nós, tão profundamente inserido no tempo que a informação sobre isso parece irreparável. "Se os pré-historiadores aceitam ou negam o caráter mágico ou religioso dos desenhos, ou a colocação deliberada ou fortuita em diferentes partes dos sistemas subterrâneos, todos os autores se acham em geral concordando que as imagens nas cavernas eram o quadro de uma ideologia associados à fertilidade e à caça”. (LEROI-GOURHAN, 1982, p.8) ${ }^{6}$.

Há uma placa descritiva sobre as formas representadas na Gruta do Ballet, em Mocambeiro/ Matozinhos - MG: "Na entrada da Gruta podem ser apreciados dois tipos de manifestação do homem pré-histórico em pintura e gravura rupestre. No teto, na parede e no bloco sobre o patamar, estão pintadas formas humanas interpretadas como o Ritual da Fecundidade, composto por fila de mulheres e crianças, fila de homens e uma cena de parto. Essas figuras foram pintadas com pigmentos minerais: oxido de Manganês (preto) e ferro (vermelho). No bloco, perto do piso, pode ser vista uma figura feita por picoteamento." Na figura 4 podem ser observadas algumas dessas representações descritas para os visitantes.

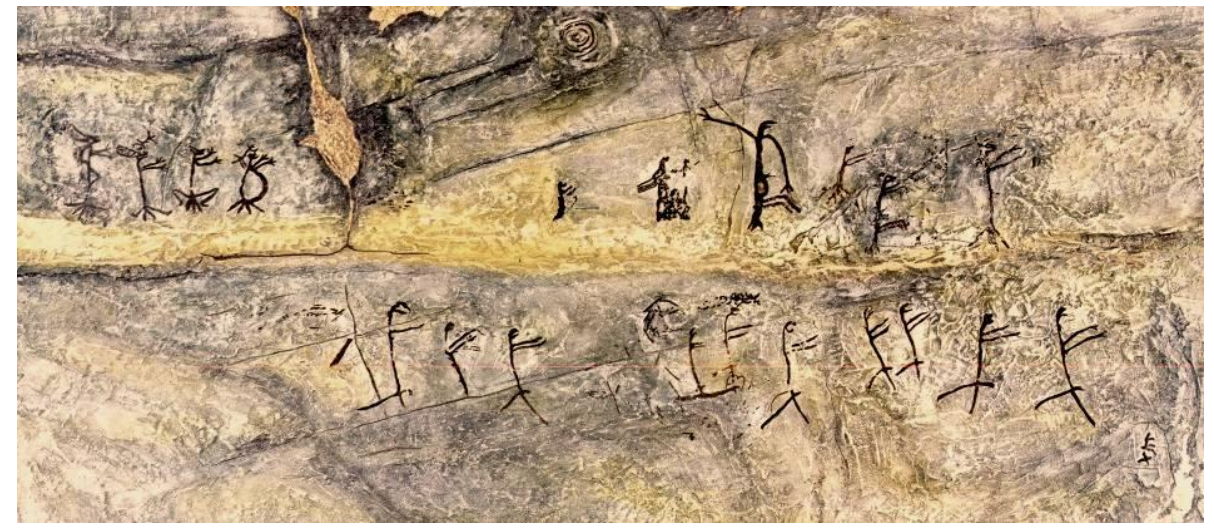

Figura 4 - Formas representadas na Gruta do Ballet, Mocambeiro/ Matozinhos - MG.

Fonte: Equipe da Pesquisa, 2016.

\footnotetext{
${ }^{6}$ Interpretação as autoras, do texto original em inglês: "Whether prehistorians accept or deny the magic or religious character of the designs, or their deliberate or fortuitous placing in different parts of subterranean systems, all authors find themselves very generally agreeing that the images in the caves were the frame of an ideology associated with fertility and hunting" (LEROI-GOURHAN, 1982, p.8).
} 
Arte rupestre é um termo utilizado para denominar as representações, consideradas artísticas, deixadas pelos homens da pré-história. São registros realizados em paredes, tetos e outras superfícies de cavernas e abrigos rochosos, ou mesmo sobre superfícies rochosas ao ar livre. A arte rupestre divide-se em dois tipos: a pintura rupestre, composições realizadas com pigmentos, e a gravura rupestre (ou "figurações rupestres", ou "inscrições rupestres"), imagens gravadas em incisões na própria rocha, conforme Pereira (2011). Exibem, em vários "estilos", técnicas e materiais uma iconografia variada. Geralmente, são representações de animais, pessoas e plantas e sinais gráficos abstratos, muitas vezes usados em combinação.

O autor relata ainda que, a interpretação desses sinais e desenhos é bastante complexa e está cercada de controvérsia. Acredita-se, pelo comportamento humano, que possam ilustrar cenas de caça, ritual, cotidiano, ter caráter mágico, e talvez expressem, enquanto linguagem visual, conceitos, valores e crenças. As figurações rupestres podem ter sido feitas com os dedos ou com a ajuda de utensílios para escavar a pedra e certamente, as cores obtidas do carvão e do óxido de ferro. Às diferentes técnicas e cores (muitas vezes superpostas) são atribuídos sentidos variados.

Essas composições, em sua maioria, são louvadas pela sua beleza e refinamento e seu apelo visual. Dessa forma, muitos pesquisadores atribuem à arte pré-histórica funções e características analisadas anteriormente, semelhantes às da arte como hoje. Embora, haja uma tendência recente para substituir a denominação "arte rupestre" por "registro rupestre", o que Endo (2009) considera coerente, pela incerteza do seu significado de origem. Todavia, permanece como testemunho precioso de culturas que exercem grande fascínio contemporaneamente, mas são ainda pouco conhecidas.

Segundo Baeta et al. (2009), no sítio Vargem da Pedra há um conjunto de figurações rupestres incomuns ou peculiares do ponto de vista estilístico, conhecidas pela população local como "pizzas coloridas", ao lado de figuras de quadrúpedes e seres humanos, típicas da região central do Estado de Minas Gerais.

Essas composições das figurações rupestres, em sua maioria, são louvadas pela população local de Mocambeiro pela sua beleza, refinamento e apelo visual. Dessa forma, muitos pesquisadores atribuem à arte pré-histórica funções e características analisadas anteriormente, semelhantes às da arte como hoje.

Contemporaneamente, há uma tendência de substituir a denominação "arte" rupestre por "figuração rupestre", ou ainda por "registro" rupestre, considerando a incerteza que cerca 
seu significado, conforme Endo (2009). Em Mocambeiro, os registros rupestres permanecem como testemunho precioso de culturas paleolíticas, ainda pouco conhecidas, que exercem grande fascínio contemporaneamente. Essas figurações rupestres foram fonte de inspiração para a arte e o artesanato produzidos nas oficinas de geração de renda e empreendedorismo da comunidade local.

Os estudos de pigmentos, formas e texturas, foi executado com a participação de membros do projeto e voluntários da pesquisa. Nesses estudos, foi verificado que pigmentos orgânicos dão resultados bem diferentes dos pigmentos artificiais. Além do estudo de formas, estaca-se que os pigmentos naturais, podem ser produzidos na comunidade. Na figura 5, alguns estudos e experimentações realizadas pela pesquisa em função das oficinas.
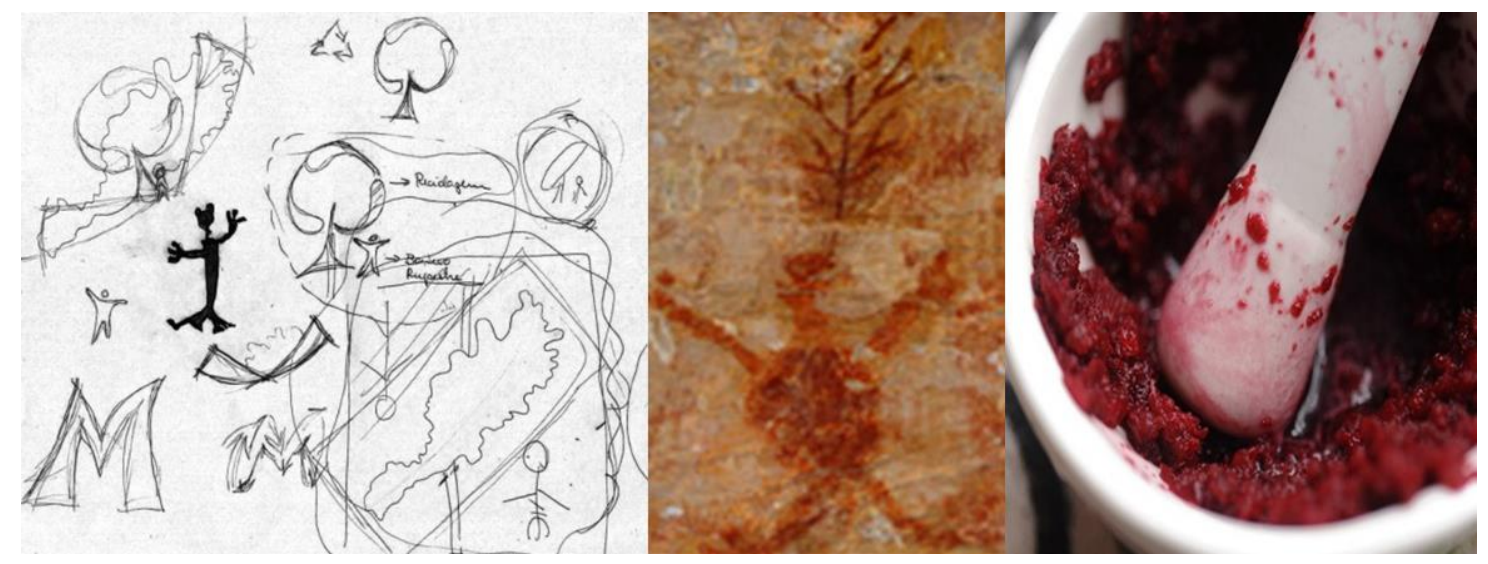

FIGURA 5 - Estudos de formas e pigmentos dos registros rupestres da região.

Fonte: Equipe da pesquisa, 2016.

\subsection{Atuação do design}

Foi realizado um estudo sobre todos os aspectos que possam influenciar a produção criativa. Buscou-se conhecer os aspectos socioculturais da região, visando à valorização da identidade e do patrimônio cultural, material e imaterial. Foi percebido que há artesãos que trabalham utilizando produtos típicos da região no artesanato local, mas ainda não há um turismo constante. Situação que não gera uma renda significativa para a região, principalmente pelo efeito da crise econômica atual.

A segunda etapa de execução do projeto de produtos artesanais de identidade territorial trata-se da realização de pesquisa das técnicas e materiais que possam ser encontrados na região de Matozinhos para recriar figurações inspiradas na arte rupestre.

Os estudos de pigmentos, formas e texturas foram executados com os membros do projeto e voluntários do CEDTec - Centro de Estudos em Design e Tecnologia da Escola de 
Design da Universidade Estadual de Minas Gerais. Foi verificado que pigmentos orgânicos dão resultados bem diferentes dos pigmentos artificiais.

$\mathrm{Na}$ terceira etapa das oficinas foram desenvolvidos carimbos ${ }^{7}$, com figurações rupestres, para estampar tecidos. Para a produção de estampas, as mulheres de Mocambeiro aprenderam sobre as possibilidades de uso de cores, destacando que os pigmentos naturais poderiam ser produzidos por elas na comunidade.

Com relação à identidade local e criatividade, foi realizado um estudo sobre todos os aspectos que possam influenciar a produção criativa. Buscou-se conhecer os aspectos socioculturais da região, visando à valorização da identidade e do patrimônio cultural, material e imaterial. Foi percebido que há artesãos que trabalham utilizando produtos típicos da região no artesanato local.

Foram realizadas palestras sobre patrimônio, identidade, memória cultural, que forneceram elementos para estimular a valorização e o empoderamento local dos participantes. Entre os resultados, conforme figura 6, observou-se a importância da memória cultural - onde se desenvolve a história, aliada ao patrimônio material e imaterial, encontra-se fonte de criatividade para os artesãos e para valorizar a identidade local. $\mathrm{O}$ artesanato com características da região se desenvolve aliado ao patrimônio material e imaterial.
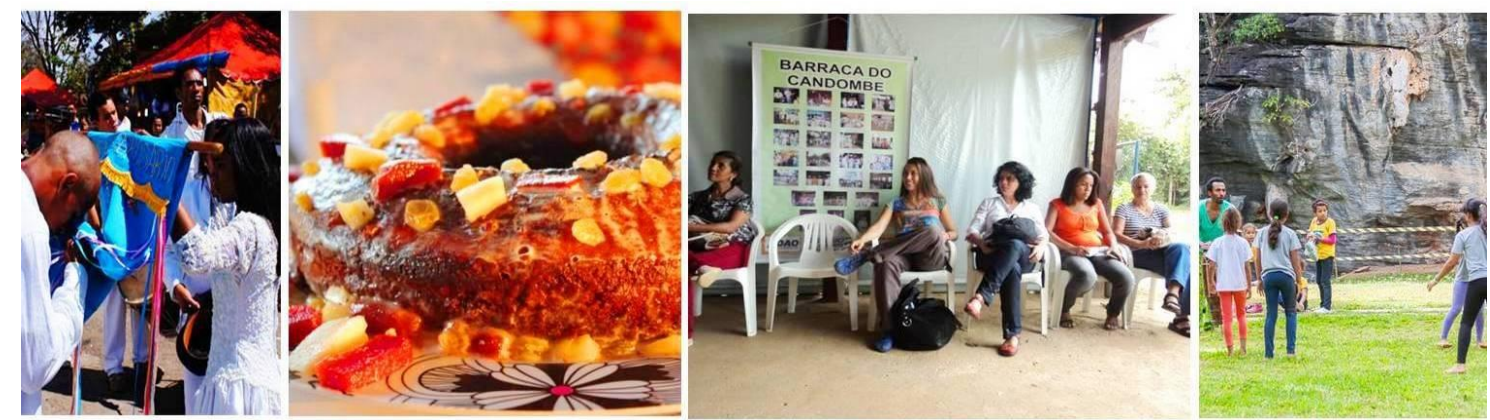

Figura 6 - Estudos sobre o patrimônio, identidade e memória cultural.

Fonte: Equipe da pesquisa, 2016.

Novas propostas se alinharam à continuidade do trabalho na comunidade de Mocambeiro, com as novas habilidades desenvolvidas pela comunidade. Além das estampas com carimbos é possível que as artesãs utilizem as figurações rupestres com fonte de

\footnotetext{
${ }^{7}$ O desenvolvimento de carimbos, a partir dos elementos da arte rupestre em Mocambeiro, foi uma prática aplicada pela professora Angela Mara Magalhães e aluno do curso de Design de Produto, João Victor Santos Araujo.
} 
inspiração para bordados, bolsas e camisetas. Dessa forma, esses produtos, além da identificação e do valor agregado pelo conhecimento do patrimônio, poderão ganhar novas formas, apresentando novas tendências em produtos.

\section{Resultados e conclusões}

Partiu-se da ideia segundo a qual os aspectos materiais do patrimônio natural e cultural do Mocambeiro constituem uma porta de entrada para a compreensão daquela sociedade e que "as coisas modelam e dão solidez às relações sociais e reciprocamente as relações sociais se expressam também através das coisas" (SARTI, 2003, p.17). Assim, promover a educação, desenvolver a qualidade de vida desta comunidade, tanto social, econômica e pessoal, valorizando o patrimônio natural e cultural ali existente, resultará num efeito positivo e necessário no desenvolvimento social, local, sustentável e pessoal.

Sabe-se que historicamente, a produção artesanal é aquela em que o uso correto das matérias-primas se faz mais presente. Observa-se que para o desenvolvimento da capacidade empreendedora ser efetiva é necessário trabalhar anteriormente a reflexão sobre os valores culturais e sociais do cidadão, o reconhecimento do patrimônio e o resgate da memória coletiva da região, para otimização de processos produtivos e do sentimento de pertencimento.

São necessários maiores investimentos na formação e capacitação dos artesãos locais, para aproveitarem o potencial inspirador das figurações rupestres existentes no local como valorização da herança que os primitivos habitantes do Paleolítico deixaram para as futuras gerações.

Valorizar a memória e as tradições amplia o pertencimento e fortalece os valores locais. Foi observado que a produção criativa do artesanato local e as novas possibilidades de atuação do design nas comunidades artesãs são práticas indispensáveis à valorização de produtos de identidade territorial.

Novas propostas se alinham à continuidade do trabalho na região de Mocambeiro, como o das habilidades da comunidade. O uso da logo (como estampa para produtos industrializados) como a sugestão em canecas, bordados com estamparias do patrimônio local, modelos de bolsas com os estudos de pintura rupestre, podem gerar tendência em produtos criativos, conforme sugestões na figura 7. 

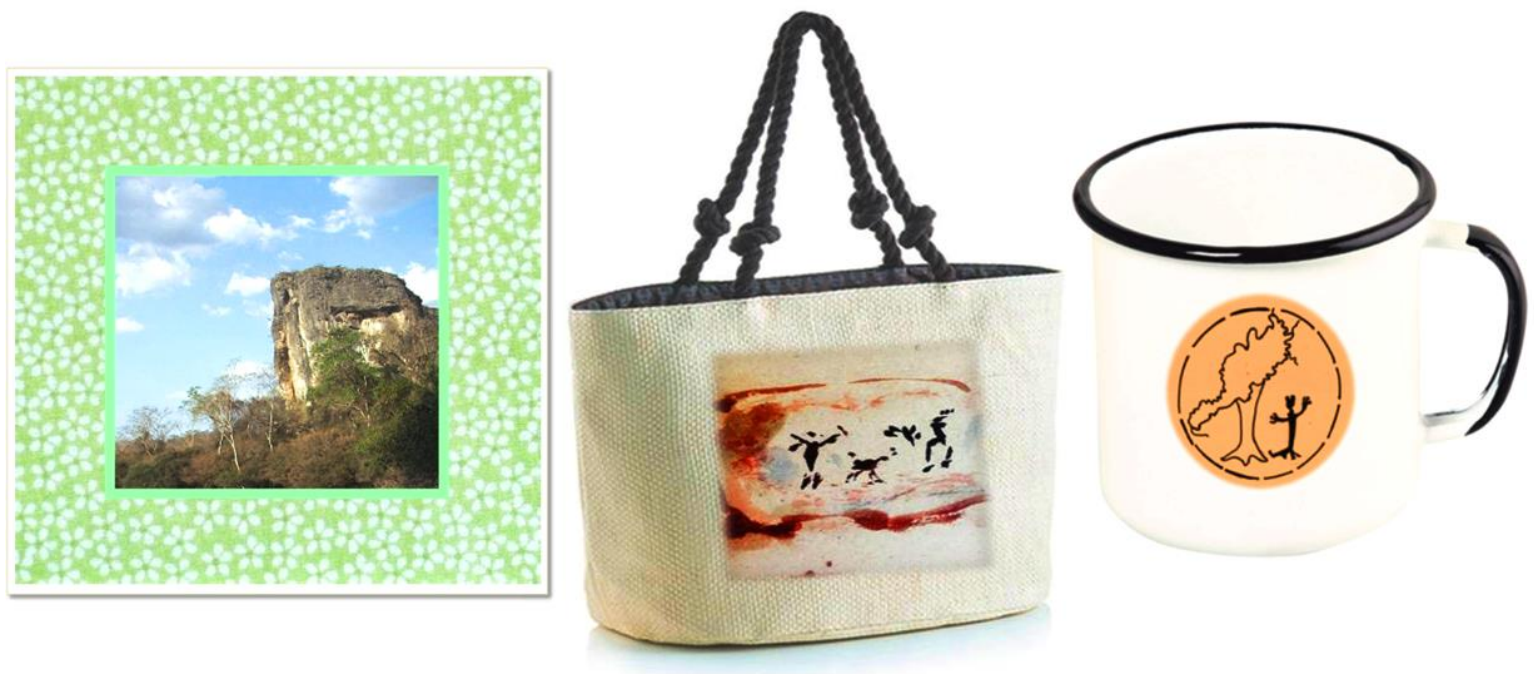

Figura 7 - Sugestões de produtos criativos.

Fonte: Equipe da Pesquisa, 2016.

O Design poderá contribuir com esse universo, ampliando as possibilidades entre os materiais e a produção criativa, para geração de renda. O design é um instrumento capaz de estabelecer caminhos de empreendedorismo humano, social, econômico e cultural. Compreende-se que, a produção criativa e as novas possibilidades de atuação do design nas comunidades artesãs, são práticas indispensáveis à construção de valorização do artesanato local, atual e do futuro.

\section{Referências}

ARANTES, A. A. Cultura e Territorialidade em Políticas Sociais. In: LAGES, V.; BRAGA, C.; MORELLI, G. (Org). Territórios em movimento: cultura e identidade como estratégia de inserção competitiva. Brasília: Relume Dumará/SEBRAE, 2004. p. 85-130.

ARMOND, M. A. Ecomuseu Mocambeiro. Postado em: 25 nov. 2012. Disponível em: http://ecomuseumocambeiro.blogspot.com.br/. Acesso em: 20 jun. 2017.

BAETA, A. et al. Estudo Técnico para a criação Monumento Natural Vargem da pedra. Belo Horizonte: IEF, 2009.

BERBERT-BORN, M. Carste de Lagoa Santa. In: Schobbenhaus, C.; Campos, D. A.; Queiroz, E. T.; Winge, M.; Berbert-Born, M. (Edit.) Sítios Geológicos e Paleontológicos do Brasil. 2000. Disponível em: http://sigep.cprm.gov.br/sitio015/sitio015.htm. Acesso em: 17 jul. 2017.

CANCLINI, N. G. Diferentes, desiguais e desconectados. Rio de Janeiro: Editora UFRJ, 2005. 
CASTRO, L. M. B. de. Representações sexuais na pré-história, Parque Nacional Serra da Capivara: padrões cenográficos. Trabalho de conclusão do Curdo de Graduação em Arqueologia e Preservação Patrimonial. Universidade Federal do Vale do São Francisco. São Raimundo Nonato, 2010.

CETEC - FUNDAÇÃO CENTRO TECNOLÓGICO DE MINAS GERAIS. A arte rupestre no Estado de Minas Gerais. Relatório Técnico, 1980.

DOMINGUES, Joelza Ester. Sítios arqueológicos pré-coloniais para visitar no Brasil, postado em 16 jan. 2016. Blog: Ensinar História.

ENDO, T. S. A pintura rupestre da pré-história e o grafite dos novos tempos. CELACC / ECA / USP, 2009.

GIL, A. C. Como elaborar projeto pesquisa. 5. ed. São Paulo: Atlas, 2003.

GOULART, E. D.; TABULEIRO, S. A do. Plano de Desenvolvimento Sustentável Município de Conceição do Mato Dentro. 2007.

GRANBEL. História de Matozinhos. Postado em: 01 fev. 2011. Disponível em: http://www.granbel.com.br/index.php/municipios-metropolitanos/102-municipio-dematozinhos-municipio-de-matozinhos/159-historia-de-matozinhosmg.html. Acesso em: 20 jun. 2017.

GUTHRIE, R. D. The Nature of Paleolithic Art. Chicago: University of Chicago Press, 2005.

IBGE-INSTITUTO BRASILEIRO DE GEOGRAFIA E ESTATÍSTICA. Minas Gerais.

Cidades. Disponível em: http://cidades.ibge.gov.br/xtras/perfil.php?codmun=314110. Acesso em: 20 jun. 2017.

\section{IEPHA/MG - INSTITUTO ESTADUAL DO PATRIMÔNIO HISTÓRICO E ARTÍSTICO DE MINAS GERAIS. Disponível em: http://www.iepha.mg.gov.br/. Acesso em: 20 jun. 2017.}

KOHLER, H.C. Geomorfologia cárstica na região de Lagoa Santa/MG. São Paulo: USP/Dep. Geografia, 1989.

LE GOFF, Jacques. História e memória. 5. ed. Campinas, SP: UNICAMP, 2003.

LEROI-GOURHAN, André.The Dawn of European Art: An Introduction to Palaeolithic Cave Painting. Trad. Italiano Sara Champion. Nova York: Cambridge University Press, 1982.

MOURÃO, N. M.; LACERDA, A. C.; GUIMARÃES, L. H.; CASTRO, F. N. O.

Empreendedorismo Social, Tecnologia Social e Design Universal: estudos para desenvolvimento de novos modelos. In: $1^{\circ}$ SIMPOSIO NACIONAL DE

EMPREENDEDORISMO SOCIAL ENACTUS BRASIL. Fortaleza/CE. Período de 07 e 08 de julho de 2016.

PEREIRA, T. Panorama da arte rupestre brasileira: o debate interdisciplinar. In: Revista de História da Arte e Arqueologia, 2011; n.16, p. 21-38.

PREFEITURA DE MATOZINHOS. Disponível em: http://matozinhos.mg.gov.br/pagina/78_Historia.html. Acesso em: 25 jun. 2017.

SADIER, B. et al. Further constraints on the Chauvet cave artwork elaboration. Proceedings of the National Academy of Sciences. U S A, 2012.

SANTOS, M. O retorno do territorio. En: OSAL: Observatorio Social de América Latina. Año 6 no. 16 (jun. 2005). Buenos Aires: CLACSO, 2005. 
SARTI, C. Vida en familia: casa, comida y vestido en la Europa moderna. Barcelona: Crítica, 2003.

WOODWARD, K. Identidade e diferença: uma introdução teórico e conceitual. In: SILVA, Tomaz Tadeu da. Identidade e Diferença. A perspectiva dos Estudos Culturais. Petrópolis: Vozes, 2000.

YÚDICE, G. A conveniência da cultura: usos da cultura na era global. Trad.: Marie-Anne Henriette Jeanne Kremer. Belo Horizonte: UFMG, 2004.

\section{Agradecimentos}

Fundação de Amparo à Pesquisa de Minas Gerais - FAPEMIG Centro de Estudos em Design e Tecnologia da UEMG - CEDTec Prefeitura de Matozinhos/MG

Associação Desenvolvimento Artes e Ofícios de Mocambeiro - ADAO 